(2) Open Access Full Text Article

\title{
Intraoperative Ocular Decompression Retinopathy During 23 Gauge Transconjunctival Vitrectomy: A Case Report
}

This article was published in the following Dove Press journal: International Medical Case Reports Journal

\author{
Lalit Agarwal (D) \\ Deepti Pradhan (DD' \\ Nisha Agrawal (iD ${ }^{2}$ \\ Ichhya Joshi $\mathbb{D}^{\prime}$ \\ Archana Kumari (1D) \\ Anamika Kushwaha (D) \\ 'Biratnagar Eye Hospital, Biratnagar, \\ Nepal; ${ }^{2}$ Taparia Eye Care, Biratnagar, \\ Nepal
}

Purpose: To report an uncommon case of intraoperative ocular decompression retinopathy (ODR).

Case report: A 48-year-old man presented with decreased vision and pain in the left eye (LE) for 10 days following trauma with a bamboo stick. He had visual acuity of counting finger close to face in the same eye, along with corneal edema, dilated pupil and posteriorly dislocated lens. Intraocular pressure (IOP) was $42 \mathrm{~mm}$ of mercury (Hg). He underwent 23gauge pars plana vitrectomy with removal of the dislocated lens. Towards the end of otherwise uneventful surgery, blot hemorrhages appeared over the posterior pole and equator. The following day, his vision was counting finger close to face and IOP was $16 \mathrm{~mm}$ of $\mathrm{Hg}$. Fundus examination revealed large blotches of hemorrhages at different levels of the retina, later confirmed by optical coherence tomography. Disc hyperfluorescence and blocked fluorescence corresponding to blot hemorrhages were seen on fundus fluorescein angiography. Blood investigations to rule out blood dyscrasias were within normal limits.

Conclusion: Ocular decompression retinopathy, though not common, has been reported to occur following various types of surgeries, especially if associated with preoperatively raised IOP. The event can also occur intraoperatively and the preoperative control of IOP is of paramount importance in the prevention of ODR.

Keywords: pars plana vitrectomy, intraoperative complication, preoperative raised intraocular pressure, retinal hemorrhages, decompression retinopathy

\section{Introduction}

Intraoperative development of superficial and deep retinal hemorrhages during pars plana vitrectomy is not a common finding and the cause of it is not well understood. First described by Fechtner et al in 1992, ${ }^{1}$ ocular decompression retinopathy (ODR) has since then been accredited with postoperative development of retinal hemorrhages following glaucoma drainage surgery in many reports.

We report a case of intraoperative ocular decompression retinopathy during 23gauge transconjunctival vitrectomy for posteriorly dislocated lens with raised intraocular pressure after trauma.

\section{Case Description}

A 48-year-old man presented with complaint of decreased vision and pain in the left eye (LE) for 10 days since a trauma with a bamboo stick. He had no history of any systemic disease. On examination, his right eye (RE) was normal. LE had a visual
Correspondence: Deepti Pradhan Biratnagar Eye Hospital, Rani, Biratnagar, Nepal

Tel +9779808119112

Email deeptiprdhn@gmail.com 
acuity of counting finger close to face with corneal edema, dilated pupil with shallow peripheral anterior chamber and posteriorly dislocated lens. Owing to hazy media, the view of the fundus was not very crisp but the disc appeared normal with a cup:disc ratio of $0.3: 1$, and the retina was flat with no visible breaks. Intraocular pressure (IOP) by Goldman applanation tonometer was $12 \mathrm{~mm}$ of mercury $(\mathrm{Hg})$ in $\mathrm{RE}$ and 42 in LE. Gonioscopy was attempted but angle structures could not be visualized clearly due to corneal edema. An ultrasound B-scan of LE showed posterior vitreous detachment with lens in vitreous cavity. The patient was prescribed oral and topical steroid and anti-glaucoma medications. His IOP reduced by only $6 \mathrm{~mm} \mathrm{Hg}$. He was taken up for sutured 23-gauge pars plana vitrectomy with dislocated lens removal. Towards the end of the surgery, there was a sudden appearance of blot retinal hemorrhages in the posterior pole and equator in an otherwise uneventful surgery.

On the first postoperative day, visual acuity in LE was counting finger close to face and IOP was $16 \mathrm{~mm} \mathrm{Hg}$. On fundus examination, large blotches of retinal hemorrhages were seen (Figure 1A). Fundus fluorescein angiography showed patches of blocked fluorescence corresponding to blot hemorrhages, normal caliber vessels, normal arterial and venous filling time and a hyperfluorescent disc. Optical coherence tomography showed retinal hemorrhages to be superficial (at the sub internal limiting membrane level) (Figure 1B) and deep with otherwise normal retinal architecture. Random blood sugar, hemoglobin, platelet count, bleeding time, clotting time, prothrombin time, international normalized ratio and peripheral blood smear were within normal limits. With these findings a diagnosis of intraoperative ODR was made.
The patient was discharged on topical antibiotics, steroids, and anti-glaucoma medications. On weekly follow up over the next 2 months, the best corrected Snellen visual acuity was 6/ 24 with +10 diopters with raised IOP (42 and 50 in last 2 visits) and disc cupping increased to 0.6 under 3 anti-glaucoma medications (timolol maleate, brimonidine, and dorzolamide). Retinal hemorrhages were slowly resolving (Figure 2). Gonioscopy revealed open angles in RE and closed angles in all quadrants in LE with the presence of $360^{\circ}$ peripheral anterior synechiae. The patient was then counseled for tube surgery.

\section{Discussion}

Ocular decompression retinopathy has been described as a rare postoperative complication seen in eyes following a sudden lowering of IOP. Here we have reported intraoperative ODR during 23-gauge pars plana vitrectomy which has rarely been reported in the literature.

Cases of postoperative ODR have been reported following 25 -gauge sutureless transconjunctival pars plana vitrectomy ${ }^{2}$ and following various surgeries including trabeculectomy/ glaucoma drainage device insertion, ${ }^{3}$ neodymium-doped yttrium aluminum garnet $(\mathrm{Nd}-\mathrm{YAG})$ laser iridotomy, ${ }^{4}$ orbital decompression surgery, ${ }^{5}$ vitrectomy, ${ }^{6}$ silicone oil removal, ${ }^{6}$ anterior chamber paracentesis, ${ }^{7,8}$ phacoemulsification, ${ }^{6,9}$ trabeculectomy and trabeculotomy, ${ }^{9}$ deep sclerectomy, ${ }^{10,11}$ goniotomy, ${ }^{12}$ and even following medical management of primary acute angle closure. ${ }^{13}$

The mean time to diagnosis of ODR is $1.5 \pm 2.0$ days following surgery, ${ }^{3}$ but occurrence as early as within minutes has been reported. ${ }^{7,8}$ In spite of the fact that fundus finding in ODR is prominent, $80 \%$ of patients are symptomless, with

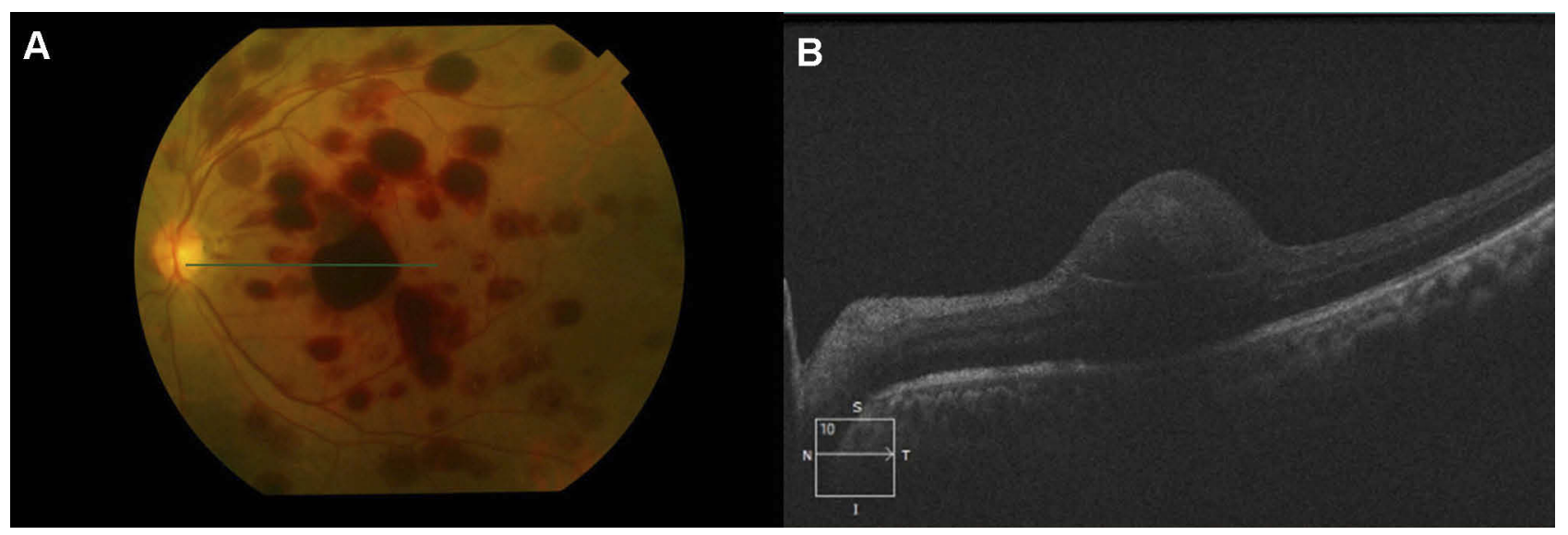

Figure I (A) Fundus photograph showing superficial and deep retinal hemorrhages over the posterior pole. (B) Spectral domain optical coherence tomogram of macula showing sub-ILM (internal limiting membrane) bleed over fovea. 


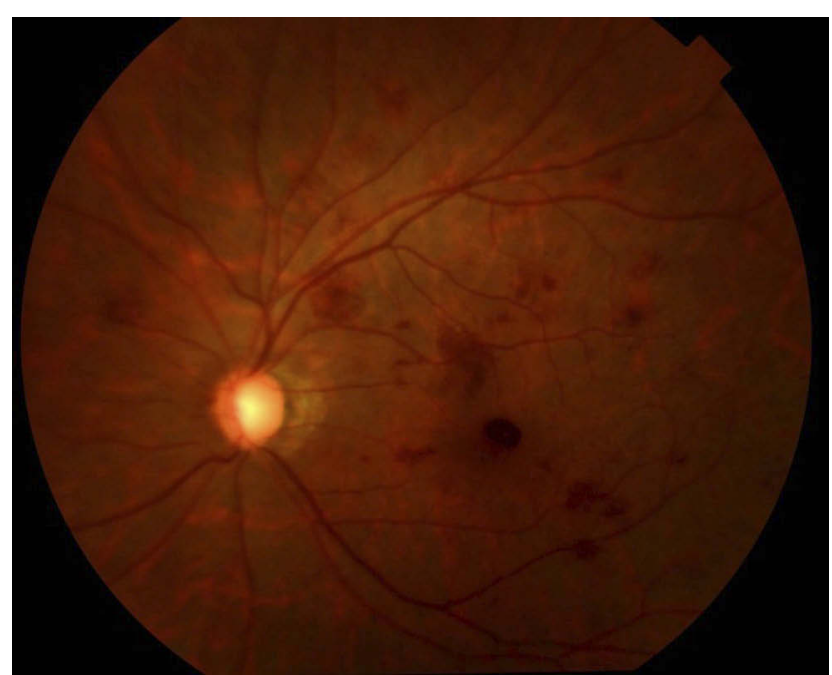

Figure 2 Fundus photo at the 2-month follow-up showing resolving retinal hemorrhages.

the remaining patients complaining of central scotoma, diminution of vision, and floaters. ${ }^{3}$ Reported fundus findings at the diagnosis of ODR include retinal hemorrhages in all layers, white centered retinal hemorrhages which are fibrin and platelet aggregates caused by capillary rupture followed by repair, subhyaloid and vitreous hemorrhage, disc hyperemia/edema and optic nerve head/peripapillary hemorrhage, as well as a few atypical ones including choroidal detachment, macular edema, and serous retinal detachment. ${ }^{3,6,9,14}$ The retinal hemorrhages associated with ODR are relatively benign with $85 \%$ of eyes regaining baseline vision.

There is no consensus regarding its pathogenesis, but mechanical and vascular theories have been proposed in an attempt to explain its different presentations. Vascular theory is based on autoregulation and fragility of retinal capillaries. The former allows fluctuation of systemic and intraocular pressure across a wide range without compromising ocular perfusion pressure. Autoregulation is lost in poorly controlled diabetes mellitus, hypertension, long-standing raised IOP and in uveitic glaucoma where breakdown of inner blood retinal barrier occurs due to long-standing inflammation. Acute reduction of IOP in such eyes leads to a reduction in arterial resistance with consequently increased blood flow, which may overwhelm the already fragile capillary bed, causing rupture. ${ }^{1,3}$ There are three mechanical theories. Gupta et al noted that with hypotony scleral collapse and globe deformity can occur, which cause mechanical shearing of capillaries leading to hemorrhage. ${ }^{7}$ The second theory involves the anterior movement of lamina cribrosa with a sudden drop in IOP, which might impede axoplasmic flow, leading to disc edema that compresses central retinal vein, and resulting in central retinal vein occlusion. ${ }^{1}$ The final theory explains the occurrence of subhyaloid/vitreous hemorrhage following YAG laser iridotomy. With the formation of peripheral iridotomy the pupillary block is released, and fluid from the posterior chamber egresses into the anterior chamber, resulting in a rapid reduction of posterior chamber volume and forward displacement of the vitreous body, causing acute posterior vitreous detachment with hemorrhage. ${ }^{3}$ Our case did not have systemic diseases but had raised IOP for more than 10 days. There might have been a loss of autoregulation and breach of inner blood-retinal barrier because of blunt trauma. With the sudden drop in IOP during surgery, an increase in arterial blood flow might have overwhelmed the resistance of capillaries, leading to retinal hemorrhages. We hereby re-emphasize the importance of adequate preoperative reduction of IOP and gradual intraoperative decompression in the prevention of ODR.

\section{Conclusion}

Development of intraoperative retinal hemorrhages during vitrectomy in the presence of preexisting posterior vitreous detachment, a normal vessel caliber with normal arteriolar and venous filling time with no retinal ischemia in fundus fluorescein angiography, and a normal hemogram point towards the diagnosis of intraoperative ODR with secondary angle closure glaucoma.

\section{Consent and Ethical Clearance}

Written informed consent was obtained from the patient for the case details and the accompanying images to be published. The Institutional Review Board was informed and approval was not required for reporting the case.

\section{Funding}

The authors received no financial support for the research, authorship, or publication of this article.

\section{Disclosure}

The authors report no conflicts of interest in this work.

\section{References}

1. Fechtner RD, Minckler D, Weinreb RN, et al. Complications of glaucoma surgery. Ocular decompression retinopathy. Arch Ophthalmol. 1992;110:965-968. doi:10.1001/archopht.1992.01080190071032

2. Rezende FA, Regis LG, Kickinger M, et al. Decompression retinopathy after 25-gauge transconjunctival sutureless vitrectomy: report of 2 cases. Arch Ophthalmol. 2007;125:699-700. doi:10.1001/archopht.125.5.699

3. Mukkamala SK, Patel A, Dorairaj S, et al. Ocular decompression retinopathy: a review. Surv Ophthalmol. 2013;58(6):505-512. doi:10.1 016/j.survophthal.2012.11.001 
4. Waheeb SA, Birt CM, Dixon WS. Decompression retinopathy following YAG laser iridotomy. Can J Ophthalmol. 2001;36:278-280. doi:10.1016/S0008-4182(01)80035-1

5. Ben Simon GJ, Goldberg RA, McCann JD. Bilateral decompression retinopathy after orbital decompression surgery. $\mathrm{Br} J$ Ophthalmol. 2004;88:1605-1606. doi:10.1136/bjo.2004.049767

6. Arevalo JF, Mendoza AJ, Fernandez CF, et al. [Decompression retinopathy after intraocular surgery]. Arch Soc Esp Oftalmol. 2007;82 (10):629-634. doi:10.4321/s0365-66912007001000007

7. Gupta R, Browning AC, Amoaku WM. Multiple retinal haemorrhages (decompression retinopathy) following paracentesis for macular branch artery occlusion. Eye. 2005;19:592-593. doi:10.1038/sj.eye.6701530

8. Prince J, Fleischman D. Immediate manifestation of ocular decompression retinopathy following anterior chamber paracentesis. Case Rep Ophthalmol. 2019;10:287-291. doi:10.1159/000501846

9. Singh K, Bhattacharyya M, Wali K, Rana K, Jain D. Ocular decompression retinopathy: a case series. Nepal J Ophthalmol. 2017;9 (2):194-198. doi:10.3126/nepjoph.v9i2.19269
10. Kozobolis VP, Kalogianni E, Katsanos A, Dardabounis D, Koukoula S, Labiris G. Ocular decompression retinopathy after deep sclerectomy with mitomycin $\mathrm{C}$ in an eye with exfoliation glaucoma. Eur J Ophthalmol. 2011;21(3):324-327. doi:10.5301/EJO.2010.5731

11. Salinas L, Chaudhary A, Mansouri K. Optical coherence tomography angiography description of ocular decompression retinopathy after deep sclerectomy in traumatic glaucoma. J Glaucoma. 2018;27 (3):297-301. doi:10.1097/IJG.0000000000000870

12. Burstein ES, Netland PA. Decompression retinopathy after goniotomy in a child. J Glaucoma. 2017;26(8):747-748. doi:10.1097/IJG. 0000000000000681

13. Alwitry A, Khan K, Rotchford A, et al. Severe decompression retinopathy after medical treatment of acute primary angle closure. $\mathrm{Br}$ J Ophthalmol. 2007;91:121. doi:10.1136/bjo.2006.100479

14. Nonoyama S, Tanito M, Katsube T, et al. Decompression retinopathy and serous retinal detachment after trabeculotomy in a patient with systemic amyloidosis. Jpn J Ophthalmol. 2009;53:73-75. doi:10. 1007/s10384-008-0606-y

\section{Publish your work in this journal}

The International Medical Case Reports Journal is an international, peer-reviewed open-access journal publishing original case reports from all medical specialties. Previously unpublished medical posters are also accepted relating to any area of clinical or preclinical science. Submissions should not normally exceed 2,000 words or 4 published pages including figures, diagrams and references. The manuscript management system is completely online and includes a very quick and fair peer-review system, which is all easy to use. Visit http://www.dovepress.com/testimonials.php to read real quotes from published authors. 